\title{
DIAGNOSA PENYAKIT SEPTICAEMIA EPIZOOTICA PADA SAPI TERNAK DENGAN TEOREMA BAYES
}

\author{
Yohanes Suban Belutowe \\ Teknik Informatika - S1. STIKOM Uyelindo Kupang \\ yosube@gmail.com
}

\begin{abstract}
Abstrak
Nusa Tenggara timur merupakan provinsi yang menjadi target pasokan daging sapi bagi Indonesia. Untuk diketahui populasi sapi sesuai data Dinas Peternakan NTT tahun 2014, sebanyak 860.731 ekor [1]. Sekitar 180 ribu ekor anak sapi lahir di NTT per tahunnya tetapi jumlah tersebut akan berkurang karena berbagai faktor. Paling banyak sebesar 4-5 persen karena penyakit [3]. Hal ini menjadi tugas yang berat bagi Kantor Dinas Peternakan Kabupaten Kupang untuk mendata dan menyaring sapi yang bebas dari berbagai penyakit. Salah satu penyakit yang sering menyerang sapi ternak atau kerbau adalah Septicaemia epizootica (SE) [4]. Dengan bantuan dari dinas kesehatan ternak, dan dokter hewan untuk memastikan sapi atau kerbau yang akan dijadikan pasokan daging bagi Indonesia benar-benar aman dan sehat untuk dikomsumsi. Namun dilihat dari jumlah sapi yang akan dilakukan test bebas penyakit, maka diperlukan banyak dokter hewan dan bayak waktu yang terbuang, karena dilakukan berbagai test laboratorium. Untuk membantu para para dokter hewan pada kantor Dinas Peternakan kabupaten Kupang, maka dalam penelitian ini dicoba untuk membuat aplikasi diagnosa penyakit SE dengan teorema Bayes. Aplikasi yang dibuat ditujukan pada peternak sapi sehingga dapat memastikan dengan cepat apakah sapi yang diternak apakah ada yang terkena penyakit dan secara tidak langsung meringankan kerja dari para relawan dan dokter hewan pada Dinas Peternakan Kabupaten Kupang Nusa Tenggara Timur.
\end{abstract}

Kata kunci: Teorema Bayes, Sistem pakar, Septicaemia epizootica (SE)

\section{PENDAHULUAN}

Penyakit Septicamaemia Epizootica (SE) banyak menyebar di daerah beriklim tropis atau daerah yang memiliki tingkat curah hujan yang tinggi contohnya Indonesia, Philippina, Thailand dan Malaysia (Negara ASIA). Semenatar yang bukan beriklim tropis seperti di Amerika kasus SE pernah dilaporkan terjadi pada kawanan ternak besar yaitu Bison. Penyakit ini juga dilaporkan di sejumlah negara Afrika seperti di negara-negara timur tengah serta negara Afrika Tengah dan Afrika Selatan [5]. Di Indonesia sendiri penyakit SE pertama kali dilaporkan pada tahun 1884, di daerah Balaraja Tangerang [6]. Dan pada daerah lainnya Bengkulu, Sumatera Utara, Riau, Jambi, dan Nusa Tenggara Timur. Peyakit SE atau yang dikalangan peternak dikenal dengan penyakit ngorok merupakan salah satu penyakit bersifat endemic yang akan menimbulkan kerugian ekonomi yang cukup besar.

Nusa Tenggara Timur (NTT) merupakan wilayah endemis SE kecuali Lembata. Setiap tahun kasus SE terjadi secara klinis. Program pemberantasan sudah dimulai sejak tahun 1984/1985 yaitu di kabupaten Sumba Timur, namun tidak jelas kelanjutannya. Tahun 2004 kembali dicanangkan program pemberantasan SE dan masih ditargetkan Pulau Sumba bebas SE pada tahun 2008, namun belum bisa dicapai [7].
Kabupaten Kupang merupakan salah satu kabupaten yang terdapat di Provinsi Nusa Tenggara Timur. Dengan iklim semi arid (5 bulan hujan dan seterusnya kemarau panjang) mengakibatkan sektor pertanian yang layak dikembangkan adalah pertanian lahan kering dengan sektor peternakan sebagai sektor unggulan guna memenuhi pasokan daging nasional [1]. Gubernur NTT telah mencanangkan bahwa Nusa Tenggara Timur akan menjadi provinsi ternak [2] maka pengembangan peternakan di Wilayah NTT khususnya Kabupaten Kupang harus terus ditingkatkan, sehingga tercapai swasembada daging sapi dan kerbau, namun di Kabupaten Kupang apabila dicermati maka telah terjadinya penurunan populasi yang salah satu penyebabnya adalah terdapat penyakit hewan menular yang biasa menginfeksi hewan sapi dan kerbau yaitu SE sehingga menyebabkan kerugian ekonomi yang sangat besar bagi peternak di Kabupaten Kupang [3].

Perkembangan Teknologi dan informasi saat ini sangat berpengaruh pada dunia kedokteran hewan. Dengan adanya teknologi komputer, maka penerapan metode atau algoritma yang rumit dapat diselesaikan dalam hitungan detik, seperti pada penelitian ini, teorema Bayes untuk kasus yang diterapkan diharapkan mampu dan cepat dalam mendiagnosa kemungkinan suatu penyakit yang 
dialami hewan peliharaan dan dapat memberikan solusi pengobatannya.

\section{KAJIAN LITERATUR}

\subsection{Teorema Bayes}

Teorema Bayes merupakan teorema yang kebanyakan digunakan untuk menghitung peluangpeluang dalam suatu hipotesis tertentu, Teorema Bayes pertama kali diperkenalkan oleh ilmuwan yang bernama Bayes yang ingin memastikan tentang dimana keberadaan Tuhan. Bayes mencari fakta tentang keberadaan Tuhan di dunia dan kemudian mengubahnya dengan nilai propabilitas dan yang akan dibandingkan dengan nilai probabilitas. Theorema Bayes ini juga merupakan dasar dari statistika Bayes yang memiliki penerapan dalam ilmu ekonomi mikro, sains, teori permainan dan kedokteran [8].

Teorema Bayes adalah teorema yang digunakan dalam statistika untuk menghitung peluang untuk suatu hipotesis. Bayes Optimal Classifier menghitung peluang dari suatu kelas dari masing-masing kelompok atribut yang ada, dan menentukan kelas mana yang paling optimal [9].

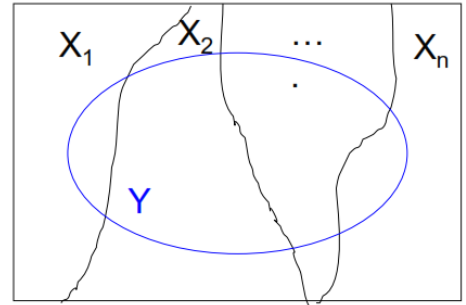

Gambar 1. Klasfikasi data

$P\left(X_{k} \mid Y\right)=\frac{P\left(Y \mid X_{k}\right)}{\sum_{i} P\left(Y \mid X_{i}\right)}$

Keadaan Posteriror (Probabilitas Xk di dalam Y) dapat dihitung dari keadaan prior (Probabilitas Y di dalam Xk dibagi dengan jumlah dari semua probabilitas $\mathrm{Y}$ di dalam semua $\mathrm{Xi}$ )

HMAP (Hypothesis Maximum Appropri Probability) menyatakan hipotesa yang diambil berdasarkan nilai probabilitas berdasarkan kondisi prior yang diketahui. HMAP adalah model penyederhanaan dari metode bayes yang disebut dengan Naive Bayes. HMAP inilah yang digunakan di dalam macine learning sebagai metode untuk mendapatkan hipotesis untuk suatu keputusan.

$$
\begin{aligned}
& P(S \mid X)=\underset{x \in X}{\operatorname{argmax}} \frac{P(Y \mid X) P(X)}{P(X)} \\
& P(S \mid X)=\underset{x \in X}{\operatorname{argmax}} P(Y \mid X) P(X)
\end{aligned}
$$

\section{Kekurangan metode Bayes [10]}

- Metode Bayes hanya bisa digunakan untuk persoalan klasifikasi yang data-datanya bersifat kategorikal dan dengan metode pembelajaran terawasi.

- Diperlukan pengetahuan awal bagi Metode Bayes untuk dapat mengambil suatu keputusan. Tingkat keberhasilannya sangat tergantung pada pengetahuan awal yang diberikan.

\subsection{Septicaemia Epizootica (SE)}

Penyakit Septicaemia Epizootica (SE) atau penyakit ngorok merupakan satu penyakit hewan menular strategis pada ruminansia besar yang ada di Indonesia dengan gejala-gejala yang muncul seperti ngorok pada malm hari, leher bengkak, keluar kelenjar dari mulut, keluar kelenjar dari hidung, tidak makan, tidak minum dan suhu tubuh panas. Di dunia penyakit ini banyak menyebar di daerah Asia yang memiliki curah hujan yang tinggi seperti Indonesia, Philippina, Thailand dan Malaysia. Di Amerika kasus SE pernah dilaporkan terjadi pada tiga kawanan Bison. Penyakit ini juga dilaporkan di sejumlah negara Afrika seperti di negara-negara timur tengah serta negara Afrika Tengah dan Afrika Selatan [4]. Di Indonesia Penyakit ini pertama kali dilaporkan pada tahun 1884, di daerah Balaraja Tangerang [5]. Penyakit SE dilaporkan terjadi di beberapa wilayah di Indonesia seperti Bengkulu, Sumatera Utara, Riau, Jambi, dan Nusa Tenggara Timur [6].

Penyakit SE disebabkan oleh infeksi bakteri yang biasa disebut para ahli hewan dengan sebutan nama gram negatif pasteurella multocida dengan serotipe tertentu. Umumnya serotype di setiap tempat memiliki perbedaan, di daerah Asia umumnya ditemukan pasteurella multocida serotype B:2 sedangkan untuk daerah Afrika biasanya ditemukan serotype E:2. Penelitian terbaru juga menyatakan bahwa terdapat serotype tipe baru yang muncul pada penyakit septicaemia epizootica yaitu serotype B:6 dan E:6. Serotype lainya dari pasteurella multocida yang dihubungkan dengan septicaemia epizootica adalah serotype A: 1 dan A: 3 , serotype ini dihubungkan dengan kematian dari sapi dan kerbau di India [4].

\subsection{Sistem Pakar}

Secara umum [10], sistem pakar adalah sistem yang berusaha mengadopsi pengetahuan manusia ke komputer yang dirancang untuk memodelkan kemampuan menyelesaikan masalah seperti yang layaknya seorang pakar. Selanjutnya, menurut Martin dan Oxman [11], sistem pakar adalah sistem berbasis komputer yang menggunakan pengetahuan, fakta dan teknik penalaran dalam memecahkan masalah yang biasanya hanya dapat dipecahkan oleh seorang pakar dalam bidang tersebut.

Penyusunannya sistem pakar harus malakukan kombinasi terhadap kaidah-kaidah untuk menarik kesimpulan atau inference rules dengan basis 
pengetahuan tertentu yang diberikan oleh satu atau lebih pakar dalam bidang tertentu. Kombinasi dari kedua hal tersebut disimpan dalam komputer, yang selanjutnya digunakan dalam proses pengambilan keputusan untuk penyelesaian masalah tertentu.

\section{METODE PENELITIAN}

\subsection{Ruang Lingkup Penelitian}

Ruang lingkup penelitian yaitu peternak hewan yang berada pada kabupaten kupang (Batakte, Tarus dan Oesao) yang masing masing diambil 10 sampel secara acak. Metde pengambilan data yaitu dengan melakukan observasi langsung wawancara dan studi pustaka.

\subsection{Diagram Konteks.}

Dalam diagram konteks metode Bayes ini akan menunjukkan hubungan antara informasi dengan lingkungan yang mengaksesnya.

Diagram konteks Diagnosa penyakit SE dengan metode Bayes dapat dilihat pada ini

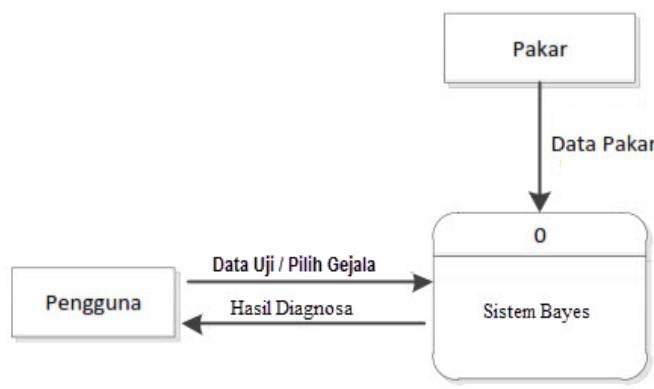

Gambar 2. Diagram Konteks

\subsection{Bagan Alir}

Pada perancangan sistem dengan metode Bayes ini, diagram arus datanya dapat dilihat pada gambar berikut ini.

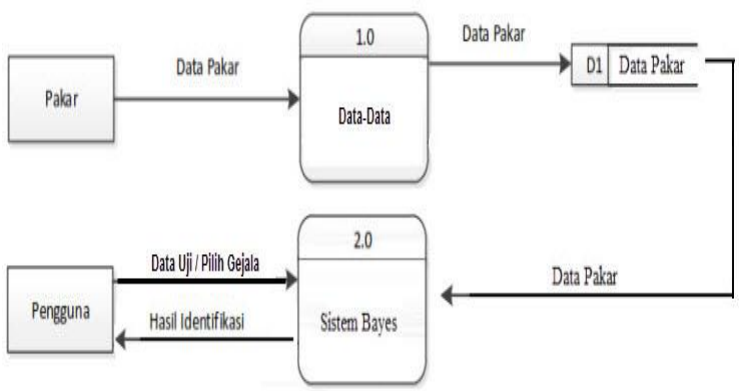

Gambar 3. Diagram Arus Data

\section{HASIL DAN PEMBAHASAN}

\subsection{Data Pakar}

Data Pakar adalah data yang diambil secara acak dari 3 lokasi penelitian di kabupaten Kupang NTT, 3 lokasi penelitian adalah Batakte, Tarus dan Oesao. Data uji yang diperoleh sebanyak 30 sampel. Selanjutnya dilakukan perhitungan nilai probabilitas dengan teorema bayes. Pada perhitungan manual, dilakukan dengan menggunakan 10 data pakar dari 30 sampel yang dipeoleh sebelumnya.
Tabel 1. Data Pakar

\begin{tabular}{c|c|c|c|l|l|l|l}
\hline $\mathrm{N}$ & $\mathrm{X} 1$ & $\mathrm{X} 2$ & $\mathrm{X} 3$ & $\mathrm{X} 4$ & $\mathrm{X} 5$ & $\mathrm{X} 6$ & $\mathrm{X} 7$ \\
\hline 1 & $\mathrm{Y}$ & $\mathrm{Y}$ & $\mathrm{Y}$ & $\mathrm{T}$ & $\mathrm{T}$ & $\mathrm{Y}$ & $\mathrm{T}$ \\
\hline 2 & $\mathrm{~T}$ & $\mathrm{~T}$ & $\mathrm{Y}$ & $\mathrm{Y}$ & $\mathrm{T}$ & $\mathrm{Y}$ & $\mathrm{Y}$ \\
\hline 3 & $\mathrm{~T}$ & $\mathrm{~T}$ & $\mathrm{~T}$ & $\mathrm{~T}$ & $\mathrm{Y}$ & $\mathrm{Y}$ & $\mathrm{Y}$ \\
\hline 4 & $\mathrm{~T}$ & $\mathrm{Y}$ & $\mathrm{Y}$ & $\mathrm{Y}$ & $\mathrm{T}$ & $\mathrm{T}$ & $\mathrm{T}$ \\
\hline 5 & $\mathrm{Y}$ & $\mathrm{Y}$ & $\mathrm{T}$ & $\mathrm{Y}$ & $\mathrm{T}$ & $\mathrm{T}$ & $\mathrm{Y}$ \\
\hline 6 & $\mathrm{Y}$ & $\mathrm{T}$ & $\mathrm{T}$ & $\mathrm{Y}$ & $\mathrm{Y}$ & $\mathrm{T}$ & $\mathrm{Y}$ \\
\hline 7 & $\mathrm{Y}$ & $\mathrm{Y}$ & $\mathrm{Y}$ & $\mathrm{T}$ & $\mathrm{Y}$ & $\mathrm{Y}$ & $\mathrm{Y}$ \\
\hline 8 & $\mathrm{~T}$ & $\mathrm{~T}$ & $\mathrm{Y}$ & $\mathrm{Y}$ & $\mathrm{Y}$ & $\mathrm{Y}$ & $\mathrm{T}$ \\
\hline 9 & $\mathrm{~T}$ & $\mathrm{~T}$ & $\mathrm{~T}$ & $\mathrm{~T}$ & $\mathrm{~T}$ & $\mathrm{Y}$ & $\mathrm{Y}$ \\
\hline 10 & $\mathrm{Y}$ & $\mathrm{Y}$ & $\mathrm{Y}$ & $\mathrm{T}$ & $\mathrm{T}$ & $\mathrm{T}$ & $\mathrm{Y}$ \\
\hline
\end{tabular}

Keterangan:

$\mathrm{N}$ : Jumlah Sampel

$\mathrm{Y}=\mathrm{Ya}, \mathrm{T}=$ Tidak

X1: Ngrorok pada malam hari $\quad$ X5: Tidak makan

X2: Leher bengkak $\quad$ X6: Tidak minum

X3: Keluar kelenjar dari mulut $\mathrm{X} 7$ : Suhu tubuh panas

X4: Keluar kelenjar dari hidung X8: Susah tidur

\subsection{Cara perhitungan dengan metode Bayes}

Bila diketahui data uiji yang diberikan adalah sebagai berikut ini.

Tabel 2. Data Uji

\begin{tabular}{l|l|l|l|l|l|l|l|l}
\hline $\mathrm{N}$ & $\mathrm{X} 1$ & $\mathrm{X} 2$ & $\mathrm{X} 3$ & $\mathrm{X} 4$ & $\mathrm{X} 5$ & $\mathrm{X} 6$ & $\mathrm{X} 7$ & $\mathrm{X} 8$ \\
\hline 1 & $\mathrm{Y}$ & $\mathrm{Y}$ & $\mathrm{T}$ & $\mathrm{Y}$ & $\mathrm{T}$ & $\mathrm{T}$ & $\mathrm{Y}$ & $?$ \\
\hline
\end{tabular}

Maka langkah pertama yang perlu dilakukan adalah dengan menghitung nilai probabilitas masing-masin variabel (x1 sampai $\mathrm{x} 7$ ) terhadap $\mathrm{x} 8$ sehingga diperoleh fakta sebagai berikut:

$\mathrm{x} 1=\mathrm{y}: \mathrm{x} 8=\mathrm{y}: 4 / 6, \mathrm{x} 1=\mathrm{y}: \mathrm{x} 8=\mathrm{t}: 3 / 4, \mathrm{x} 2=\mathrm{t}: \mathrm{x} 8=\mathrm{y}: 4 / 6$, $\mathrm{x} 2=\mathrm{t}: \mathrm{x} 8=\mathrm{t}: 1 / 4, \quad \mathrm{x} 3=\mathrm{t}: \mathrm{x} 8=\mathrm{y}: 2 / 6, \mathrm{x} 3=\mathrm{t}, \mathrm{x} 8=\mathrm{t}: 2 / 4$, $\mathrm{x} 4=\mathrm{t}: \mathrm{x} 8=\mathrm{y}: 4 / 6, \mathrm{x} 4=\mathrm{t}: \mathrm{x} 8=\mathrm{t}: 1 / 4, \mathrm{x} 5=\mathrm{y}: \mathrm{x} 8=\mathrm{y}: 3 / 6$, $\mathrm{x} 5=\mathrm{y}: \mathrm{x} 8=\mathrm{t}: 1 / 4, \mathrm{x} 6=\mathrm{y}: \mathrm{x} 8=\mathrm{y}: 6 / 6, \mathrm{x} 6=\mathrm{y}: \mathrm{x} 8=\mathrm{t}: 0$, $\mathrm{x} 7=\mathrm{t}: \mathrm{x} 8=\mathrm{y}: 2 / 6, \mathrm{x} 7=\mathrm{t}: \mathrm{x} 8=\mathrm{t}: 1 / 4$.

Selanjutnya menggunakan Hypothesis Maximum Appropri Probability (HMAP) untuk mendapatkan hipotesisnya:

a. variabel $(x 1-x 7)$ yang bernilai $y$, untuk $x 8$ yang bernilai $\mathrm{y}$.

b. variabel (x1-x7) yang bernilai t, untuk $x 8$ yang bernilai $\mathrm{y}$.

c. variabel $(\mathrm{x} 1-\mathrm{x} 7)$ yang bernilai $\mathrm{t}$, untuk $\mathrm{x} 8$ yang bernilai $\mathrm{t}$.

d. variabel (x1-x7) yang bernilai $y$, untuk x8 yang bernilai $t$.

Hasil perhitungan HMAP adalah sebagai berikut:

a. $\mathrm{x} 1 . . \mathrm{x} 2$ : $\mathrm{y}$ dan $\mathrm{x} 8: \mathrm{y}=0.167$

b. $\mathrm{x} 1 . . \mathrm{x} 2: \mathrm{t}$ dan $\mathrm{x} 8: \mathrm{y}=0.049$,

c. $\mathrm{x} 1 . . \mathrm{x} 2$ : $\mathrm{t}$ dan $\mathrm{x} 8: \mathrm{t}=0.0078$,

d. $x 1 . . x 2$ : $y$ dan $x 8: t=0.187$

Nilai HMAP kemudian dikelompokkan sesuai nilai $\mathrm{x} 8$,

a. $\quad$ 1..x2: y dan $x 8: y=0.167$ dan $x 1 . . x 2: t$ dan $\mathrm{x} 8: \mathrm{y}=0.049$. maka total nilainya $=$ 0.19 untuk $\mathrm{x} 8=\mathrm{y}$

b. $\quad x 1 . . x 2$ : $y$ dan $x 8: t=0.187$ dan $x 1 . . x 2$ : $t$ dan $\mathrm{x} 8: \mathrm{t}=0.0078$, maka total nilainya $=0.10$ untuk $\mathrm{x} 8=\mathrm{t}$ 
Lankah terakhir adalah dengan membandingkan hasil HMAP untuk kelas y dan t, maka $0.19>0.10$ dengan demikian dipastikan untuk data uji pada tabel 2 , hasilnya adalah $\mathrm{x} 8=\mathrm{y}$. Artinya data uji yang diberikan menghasilkan kesimpulan hewan tersebut positif terkena penyakit SE.

\subsection{Diagnosa dengan Program.}

Program diagnosa penyakit Septicaemia Epizootica (SE)[12] dengan metode Bayes ini dilengkapi dengan data pakar yang berguna untuk memasukan data pakar (supervised learning). Data pakar ini digunakan untuk melatih sistem agar menghasilkan nilai probabilitas dan hipotesis.

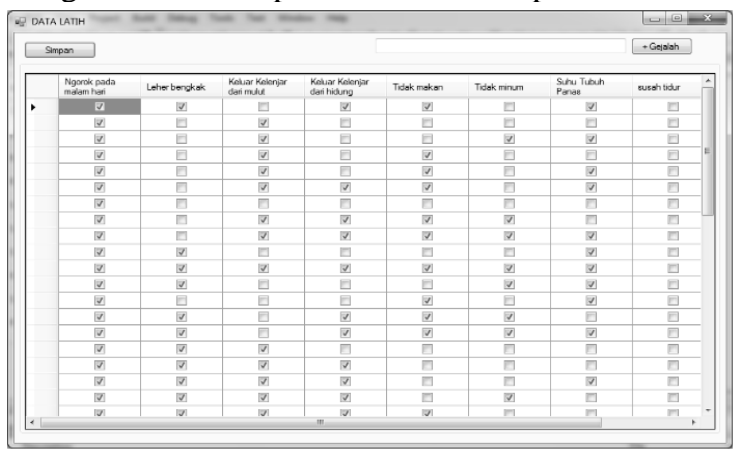

Gambar 4. Proses pemasukan data pakar

Setelah memasukan data pakarnya (data latih), berikutnya masuk dalam mode diagnosa. Mode diagnosa ini digunakan untuk mengetahui hasil dari data uji yang dimasukan. Data uji bukan dari data latih sebelumnya.

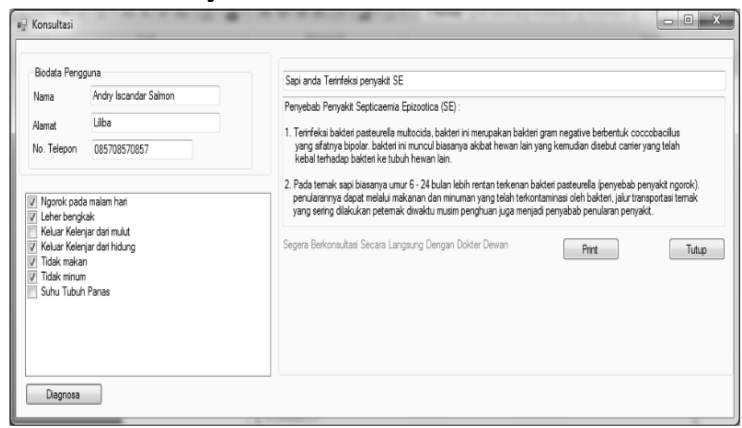

Gambar 5. Proses pemasukan data Uji dan Hasilnya

Setelah melakukan pengujian terhadap 10 data uji, maka hasil diagnose dapat dilihat pada table hasil berikut ini.

Tabel 2. Hasil Diagnosa dengan Metode Bayes

\begin{tabular}{|c|c|c|c|c|c|c|c|c|c|}
\hline $\mathrm{N}$ & $\mathrm{X} 1$ & $\mathrm{X} 2$ & $\mathrm{X} 3$ & $\mathrm{X} 4$ & $\mathrm{X} 5$ & $\mathrm{X} 6$ & $\mathrm{X} 7$ & $\mathrm{X} 8$ & $\mathrm{Y}$ \\
\hline 1 & $\mathrm{Y}$ & $\mathrm{Y}$ & $\mathrm{T}$ & $\mathrm{Y}$ & $\mathrm{T}$ & $\mathrm{T}$ & $\mathrm{Y}$ & $\mathrm{T}$ & $\mathrm{Y}$ \\
\hline 2 & $\mathrm{~T}$ & $\mathrm{~T}$ & $\mathrm{Y}$ & $\mathrm{Y}$ & $\mathrm{Y}$ & $\mathrm{Y}$ & $\mathrm{T}$ & $\mathrm{Y}$ & $\mathrm{T}$ \\
\hline 3 & $\mathrm{Y}$ & $\mathrm{Y}$ & $\mathrm{Y}$ & $\mathrm{T}$ & $\mathrm{T}$ & $\mathrm{T}$ & $\mathrm{Y}$ & $\mathrm{T}$ & $\mathrm{Y}$ \\
\hline 4 & $\mathrm{~T}$ & $\mathrm{~T}$ & $\mathrm{~T}$ & $\mathrm{~T}$ & $\mathrm{Y}$ & $\mathrm{Y}$ & $\mathrm{Y}$ & $\mathrm{Y}$ & $\mathrm{T}$ \\
\hline 5 & $\mathrm{Y}$ & $\mathrm{Y}$ & $\mathrm{Y}$ & $\mathrm{T}$ & $\mathrm{T}$ & $\mathrm{Y}$ & $\mathrm{T}$ & $\mathrm{Y}$ & $\mathrm{Y}$ \\
\hline 6 & $\mathrm{Y}$ & $\mathrm{T}$ & $\mathrm{T}$ & $\mathrm{Y}$ & $\mathrm{Y}$ & $\mathrm{T}$ & $\mathrm{Y}$ & $\mathrm{T}$ & $\mathrm{Y}$ \\
\hline 7 & $\mathrm{~T}$ & $\mathrm{~T}$ & $\mathrm{Y}$ & $\mathrm{Y}$ & $\mathrm{T}$ & $\mathrm{Y}$ & $\mathrm{Y}$ & $\mathrm{Y}$ & $\mathrm{Y}$ \\
\hline 8 & $\mathrm{~T}$ & $\mathrm{~T}$ & $\mathrm{~T}$ & $\mathrm{~T}$ & $\mathrm{~T}$ & $\mathrm{Y}$ & $\mathrm{Y}$ & $\mathrm{Y}$ & $\mathrm{T}$ \\
\hline 9 & $\mathrm{~T}$ & $\mathrm{Y}$ & $\mathrm{Y}$ & $\mathrm{Y}$ & $\mathrm{T}$ & $\mathrm{T}$ & $\mathrm{T}$ & $\mathrm{T}$ & $\mathrm{T}$ \\
\hline 10 & $\mathrm{Y}$ & $\mathrm{Y}$ & $\mathrm{Y}$ & $\mathrm{T}$ & $\mathrm{Y}$ & $\mathrm{Y}$ & $\mathrm{Y}$ & $\mathrm{Y}$ & $\mathrm{Y}$ \\
\hline
\end{tabular}

Dari 10 data uji, dapat yang didiagnosa terkena penyakit Septicaemia Epizootica (SE) sebanyak 6 sapi dan 4 tidak terkena penyakit SE.

\section{KESIMPULAN}

1. Sistem yang dibangun dengan metode Bayes ini dapat mendiagnosa penyakit Septicaemia Epizootica (SE) dengan pasti.

2. Penggunaan metode Bayes ini juga untuk menghindari ketidak pastian pada data uji, sehingga hasil dapat dikatakan akurat.

3. Metode Bayes dapat bekerja sesuai data awal yang diberikan, sehingga masuk dalam model supervised learning.

4. Tingkat keakurasian dalam teorema Bayes tergantung dari data awal yang diberikan.

\section{TERIMA KASIH}

Penulis mengucapkan terima kasih kepada Kepala Dinas Peternakan Kabupaten Kupang, yang telah memberikan kemudahan dalam penelitian di Batakte, Tarus dan Oesao. Terima juga penulis ucapkan kepada peternak sapi di daerah Batakte, Tarus dan Oesao yang memberikan kesempatan untuk mengambil sampel pada ternak mereka.

\section{REFERENSI}

[1] http://bisnis.tempo.co/read/news/2015/08/16/0 90692354/pengiriman-sapi-ntt-tidak-dibatasikuota-65ribu-ekor-tahun, Diakses pada tangga 23 Desember 2015

[2] http://www.disnakprovntt.web.id. Diakses pada tanggal 23 Desember 2015

[3] http://www.rmol.co/read/2015/11/17/224961/ NTT-Siap-Penuhi-Kebutuhan-Daging-SapiDKI-, Diakses pada tangga 23 Desember 2015

[4] LILY NATALIA dan ADIN PRIADI, Lokakarya Nasional Ketersediaan IPTEK dalam Pengendalian Penyakit Stategis pada Ternak Ruminansia Besar, Balai Penelitian Veteriner PO Box 151 Bogor 16114, 2007

[5] OIE (The World Organization For Animal Health), 2009, Haemorragic septicaemia. http://www.oie.int/animal-health-in-theworld/teckniacial- disease-cards/. Diakses pada tanggal 23 Desember 2015.

[6] Direktorat Kesehatan Hewan, Septicaemia epizootica (SE) dalam Pedoman Pengendalian Penyakit Hewan Menular, Lokakarya Penyusunan Pedoman Pengendalian Penyakit Hewan Menular, Cisarua, Bogor, 1997

[7] Berek, H.S.D., 2010, Prevalensi Kekebalan Terhadap Septicaemia Epizootica pada Sapi di Kabupaten Kupang, Tesis, Program Studi Sain Veteriner, UGM, Yogyakarta.

[8] Mulyanto, E., Theorema Bayes, Andi Offset, Yogyakarta, 2010

[9] Turban,E.,Aronson,J. dan Peng L., Decision Support System and Intellegence System-7th Ed, Pearson education, New Jersey, 2005 
[10] Turban, E., Decision Support System and Expert System, Edisi 7, Andi, Jakarta, 2005.

[11] Kusrini, Sistem Pakar Teori dan Aplikasi, Andi, Yogyakarta, 2006.

12 Andry Iscandar Salmon, Penerapan Metode Bayes Untuk Diagnosis Penyakit Septicaemia Epizootica Pada Hewan Ruminansia Besar, Skripsi, Teknik Informatika - S1, STIKOM Uyelindo, 2015 